\title{
Gas Phase Oligomerization of Isobutene over Acid Treated Kaolinite Clay Catalyst
}

\author{
Dhaifallah Aldhayan, Ahmed Aouissi* \\ Department of Chemistry, King Saud University, P.O. Box 2455, Riyadh-11451, Saudi Arabia
}

Received: 27th October 2016; Revised: 21 ${ }^{\text {st }}$ December 2016; Accepted: $22^{\text {nd }}$ December 2016

\begin{abstract}
Natural Kaolin Clay was calcined and treated by sulfuric acid. The resulting solid acid catalyst was characterized by FTIR, TGA, and X-ray powder diffraction (XRD) and tested for isobutene oligomerization in a gas phase. The characterization results showed that the acid treated clay underwent chemical and structural transformations. After acid treatment, the $\mathrm{Si} / \mathrm{Al}$ ratio was increased, and the crystalline raw clay became amorphous. The effects of various parameters such as reaction temperature, reaction time and contact time on isobutene oligomerization were investigated. Catalytic tests showed that isobutene oligomerization led to dimers and trimers as major products. Tetramers were obtained as byproducts. At relatively high reaction temperatures and long contact times, the conversion was enhanced while the selectivity of dimers was decreased in favor of higher oligomers. Copyright (C) 2017 BCREC GROUP. All rights reserved
\end{abstract}

Keywords: Isobutene; Oligomerization; Clean gasoline; Clay catalyst; Solid acid catalyst

How to Cite: Aldhayan, D., Aouissi, A. (2017). Gas Phase Oligomerization of Isobutene over Acid Treated Kaolinite Clay Catalyst. Bulletin of Chemical Reaction Engineering \& Catalysis, 12 (1): 119126 (doi:10.9767/bcrec.12.1.758.119-126)

Permalink/DOI: http://dx.doi.org/10.9767/bcrec.12.1.758.119-126

\section{Introduction}

The quality of fuels has been improved by the addition of methyl tert-butyl ether (MTBE) as the preferred additive. However, because of the contamination it caused in groundwater, it has been banned in California since 2004 due to the new regulations of the agency of environmental protection (EPA) [1]. The removal of this ether will cause considerable problems in refineries as they will face the challenge of producing fuels having the desirable properties that meet the increasing environmental regulations and health restrictions on engine emissions [2].

The production of oligomers, such as dimers and trimers from isobutene, is a very promising

* Corresponding Author.

E-mail: aouissed@yahoo.fr

Telp.: +96614675958 Fax.: +96614675992 process for upgrading isobutene (IB). An advantage of this process is that the IB is available from fluid catalytic cracking, steam cracking and isobutane dehydrogenation. Moreover, IB is available in excess because it is one of the main raw materials used for the synthesis of MTBE. Diisobutenes (dimers) and triisobutenes (trimers), for example, after hydrogenation, can be used as additives for the production of gasoline, kerosene and jet fuel with a high quality $[3,4]$. As the obtained products are the cleanest fuels produced in a refinery, they are highly desired, both economically and environmentally. The commercial importance of this process has led to the search for new solid acid catalysts that can enhance the selectivity of the desired products (diisobutene and triisobutenes). As olefin dimerization and trimerization are reactions for which the activity and selectivity strongly depend on the catalyst acidity, treat- 
ment of various oxides with sulfates, tungstates or phosphates has been widely recommended by several authors to modify the acidic properties [5-7]. Several solid acid catalysts such as titanium oxide [5,8] and zirconium oxide [6,9,10], heteropoly acid [11], and zeolites [12-14] have been suggested for the dimerization and trimerization reaction. In the present work, Saudi kaolinite clay has been treated by sulphuric acid and tested as solid acid catalyst for the oligomerization of isobutene.

\section{Experimental Section}

\subsection{Catalysts preparation}

The $10 \mathrm{~g}$ sample of silty clay soil collected from Al-Kharj district south of Riyadh in Saudi Arabia was acidified with $4.5 \mathrm{M}$ sulfuric acid solution. For acidification the samples was heated under reflux at $70{ }^{\circ} \mathrm{C}$ for $2 \mathrm{~h}$ with stirring. The acidified soil sample was centrifuged at $3000 \mathrm{rpm}$ for $10 \mathrm{~min}$ to separate the soil as a precipitate then washed twice with warm distilled water and centrifuged again at the same speed and time then followed with drying at 80 ${ }^{\circ} \mathrm{C}$ for $48 \mathrm{~h}$ and saved desiccated for analyses after calcination at $450{ }^{\circ} \mathrm{C}$ for $2 \mathrm{~h}$ in tube furnace under air flow $80 \mathrm{~mL} / \mathrm{min}$.

\subsection{Catalysts characterization}

Characterization was performed by means of FT-IR, XRD, TGA, and surface area measurement. IR spectra were recorded with an infrared spectrometer GENESIS II- FTIR (4000$400 \mathrm{~cm}^{-1}$ ) as $\mathrm{KBr}$ pellets. XRD powder patterns were recorded on an Ultima IV, X-ray diffractometer: Rigaku) using $\mathrm{Cu}-\mathrm{Ka}$ radiation. XRF analyses of the samples were done using a Model-58 Tiger of Bruker make, with X-ray tube of rhodium anode and scintillation detector with a current $10 \mathrm{~mA}$ and voltage $40 \mathrm{kV}$. Thermogravimetric analysis (TGA) was carried out on a PERKIN-ELMER TGA instrument with a heating rate of $5 \mathrm{~K} / \mathrm{min}$ in flowing $\mathrm{N}_{2}$. Surface area measurement BET was determined by V-Sorb 2800 Porosimetry Analyser.

\subsection{Catalyst testing}

The catalytic activity of the kaolin catalyst for the isobutene oligomerization was performed using a continuous-flow fixed bed reactor at atmospheric pressure. The catalyst (50 to $250 \mathrm{mg}$ ), with an average particle diameter ranging from 0.01 to $0.8 \mathrm{~mm}$ was loaded in a stainless steel reactor and held by means of glass wool. The reactor was heated electrically by a tubular furnace and the reaction tempera- ture was measured by a thermocouple placed on the outer wall of the catalytic bed. Then, isobutene (99.5\% purity) was admitted into the reactor with a flow of $100 \mathrm{~mL} / \mathrm{min}$. The reaction products which were condensed using a cold trap $\left(-15{ }^{\circ} \mathrm{C}\right)$, were collected every hour for $5 \mathrm{~h}$ and analyzed with a gas phase chromatograph PYE UNICAM) equipped with a flame ionization detector using a capillary column (HP-PLOT Q length of $30 \mathrm{~m}$ ID of $0.53 \mathrm{~mm}$ ). The identification of the products was achieved occasionally by Gas chromatography-mass spectrometry (GC-MS) using a Thermo Trace GC Ultra gas chromatograph equipped with AI 3000. For the separation of target compounds, a TR-5 MS-SQC capillary column $(30 \mathrm{~m} \times 0.25$ $\mathrm{mm}$ i.d., phase thickness $0.25 \mu \mathrm{m})$ was used with helium as the carrier gas (at a flow rate of $1 \mathrm{~mL} / \mathrm{min}$ ).

\section{Results and Discussion}

\subsection{Catalyst characterizations}

\subsubsection{XRF characterization}

The chemical composition of the raw and acid treated clay is shown in Table 1 . It can be seen that both samples are constituted of $\mathrm{SiO}_{2}$ and $\mathrm{Al}_{2} \mathrm{O}_{3}$ as major components. Iron oxide, titanium oxide, magnesium oxide, calcium oxide and potassium oxides are present as minor oxides suggesting the presence of illite mineral. After acid treatment the composition of the raw clay changes significantly.

The $\mathrm{Al}_{2} \mathrm{O}_{3}, \mathrm{MgO}, \mathrm{CaO}$ and $\mathrm{Na}_{2} \mathrm{O}$ contents in the acid treated material decrease. Taking into account the reaction between kaolinite and sulfuric acid $\left(\mathrm{Al}_{2} \mathrm{O}_{3} \cdot 2 \mathrm{SiO}_{2} \cdot 2 \mathrm{H}_{2} \mathrm{O}+3 \mathrm{H}_{2} \mathrm{SO}_{4} \rightarrow\right.$ $\mathrm{Al}_{2}\left(\mathrm{SO}_{4}\right)_{3}+2 \mathrm{SiO}_{2}+5 \mathrm{H}_{2} \mathrm{O}$ [15]), one can see that the decrease in the alumina content in the acid treated sample might be due to the leaching of the $\mathrm{Al}^{3+}$ ions from the octahedral layer by hydrolysis reaction under acidic conditions. This result is in agreement with that of Volzone et al. [16]. In fact, in the opinion of the authors, when the acid strength is in the range of 3-5 M, the octahedral layer is strongly attacked leading to rapid solubility of $\mathrm{Al}$. As for $\mathrm{SiO}_{2}$, its content was increased after acid treatment due to which the Si/Al ratio increased. The potash remaining in the acid treated clay material indicated that the illite clay mineral was still in the structure of the clay material, as also confirmed by XRD patterns (Figure 2).

\subsubsection{FT-IR characterization}

The FTIR spectra of the kaolinite clay before and after treatment are shown in Figure 1. 
The bands at $3696 \mathrm{~cm}^{-1}(\mathrm{OH}$ stretching), 3423 $\mathrm{cm}^{-1}\left(\mathrm{H}-\mathrm{O}-\mathrm{H}\right.$ stretching) $\mathrm{cm}^{-1}$ correspond to valence vibrations of surface hydroxyl clusters; the bands at $3620 \mathrm{~cm}^{-1}$ and $919 \mathrm{~cm}^{-1}(\mathrm{OH}$ stretch) are assigned to the vibrations of the internal hydroxyl cluster [17,18]. The well resolved high-intensity lines in the range of 1109 $\mathrm{cm}^{-1}$ (Si-O stretch) and 1040 (Si-O stretch), correspond to the vibrations (Si-O) [19]. The bands at $526 \mathrm{~cm}^{-1}$ (Si-O-Al deformation), 469 $\mathrm{cm}^{-1}$ ( $\mathrm{Si}-\mathrm{O}$ bending) $\mathrm{cm}^{-1}$ are typical of kaolinite clay mineral $[15,20,21]$. The band at $1629 \mathrm{~cm}^{-1}$ corresponds to the quartz phase. The two bands observed at $1432 \mathrm{~cm}^{-1}$ and $876 \mathrm{~cm}^{-1}$ assigned to the vibration of $\mathrm{CO}_{3}{ }^{2-}$, indicate the presence of potassium carbonate [22]. Compared to the raw kaolinite clay, the acid treated sample showed some changes: the intensities of the broad band at $3423 \mathrm{~cm}^{-1}$ and the peaks at $526 \mathrm{~cm}^{-1}$ and 469 $\mathrm{cm}^{-1}$ increased, while those at $1432 \mathrm{~cm}^{-1}$ and $876 \mathrm{~cm}^{-1}$, characteristic of carbonates decreased. The decrease of the latter was due to the thermal instability of carbonates [23]. These changes in the IR spectrum are in agreement with the results obtained by elemental analyses and TGA.

Table 1. Chemical composition of raw and acid treated kaolinite clay.

\begin{tabular}{ccc}
\hline \multirow{2}{*}{ Chemical content $(w t \%)$} & \multicolumn{2}{c}{ Material } \\
\cline { 2 - 3 } & Raw clay & Treated clay \\
\hline $\mathrm{SiO}_{2}$ & 44.12 & 49.26 \\
$\mathrm{Al}_{2} \mathrm{O}_{3}$ & 31.62 & 28.66 \\
$\mathrm{Fe}_{2} \mathrm{O}_{3}$ & 13.50 & 11.29 \\
$\mathrm{CaO}$ & 2.85 & 0.005 \\
$\mathrm{~K}_{2} \mathrm{O}$ & 3.72 & 0.038 \\
$\mathrm{TiO}_{2}$ & 1.49 & 0.02 \\
$\mathrm{MgO}$ & 0.008 & 0.005 \\
$\mathrm{Na}_{2} \mathrm{O}$ & 0.008 & 0.00009 \\
$\mathrm{P}_{2} \mathrm{O}_{5}$ & 1.06 & 0.041 \\
$\mathrm{ZrO}_{2}$ & 0.0006 & traces \\
\hline
\end{tabular}

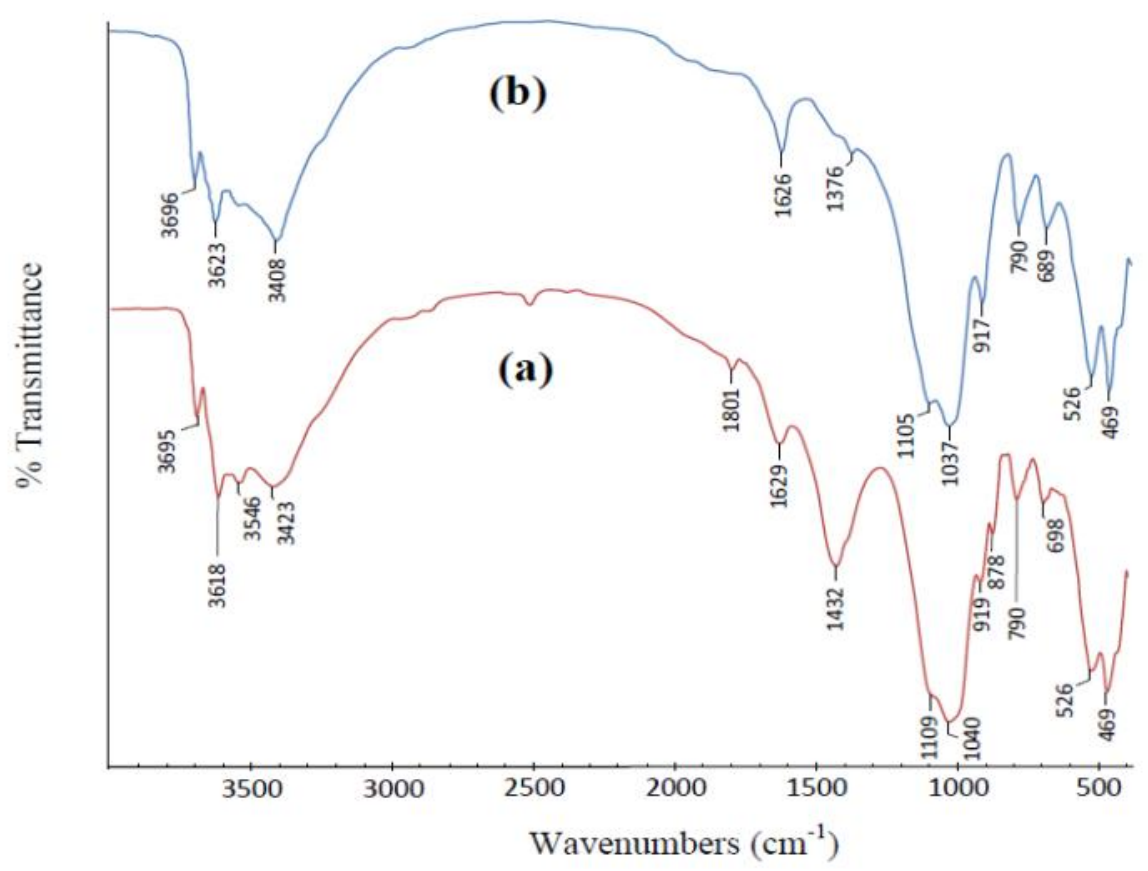

Figure 1. IR spectra of raw (a) and acid treated kaolinite clay (b). 


\subsubsection{X-ray powder diffraction}

Figure 2 presents the XRD patterns of the clay before and after acid treatment. Both clay samples showed kaolinite as well as illite phases as clay minerals, and quartz as impurity [24]. The major peaks are associated to kaolinite $(\mathrm{K})$ whereas the minor peaks are associated to quartz (Q) and illite (I). This is in agreement with most clay found in Saudi Arabia $[25,26]$. The relatively high intensity of the quartz peaks in the clay samples indicates a significant presence of the free silica. These results are in agreement with those reported in the literature [24,26]. The acid treated clay mineral is less ordered than the raw clay, as it is indicated by the shape of peaks in XRD range $20-25^{\circ}(2 \theta)$ [27]. It has been shown by XRD characterization that the acid treated clay underwent structural transformation. The crystallinity and the interlayer structure of the clay material were found to be altered with acid treatment at and above $5 \mathrm{M}$ concentrations. The crystalline pure clay became amorphous [28].

\subsubsection{Thermogravimetric analysis}

TGA profile of parent and acid treated clay (Figure 3) show two weight loss regions, below $200{ }^{\circ} \mathrm{C}$ and above $450{ }^{\circ} \mathrm{C}$. The weight loss was due to three kinds of water molecules in the clay structure. The first weight loss which occurred below $200{ }^{\circ} \mathrm{C}$ corresponds to the removal of the physisorbed water. The second was due to the water molecules present in the first coordination sphere of the interlayer ions strongly bonded which requires higher temperatures in

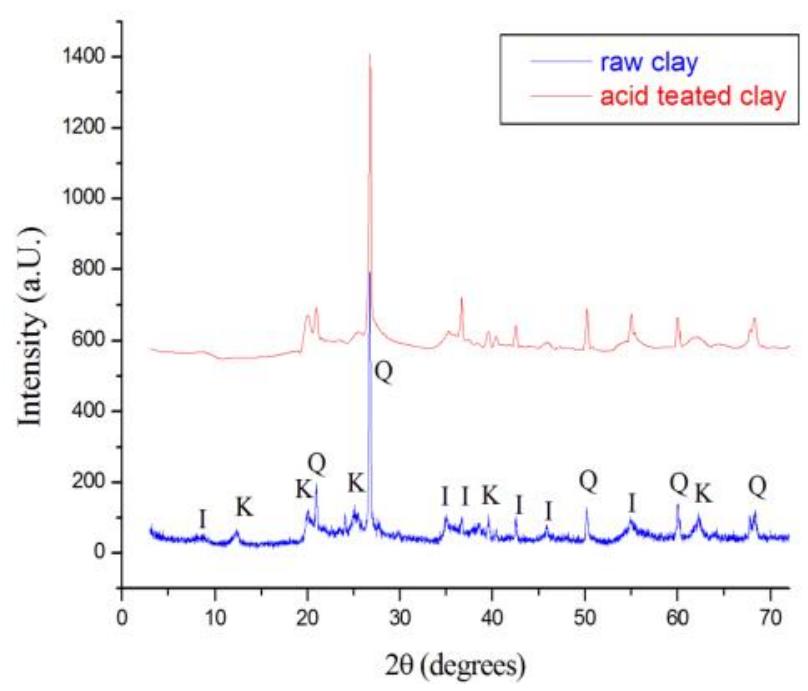

Figure 2. XRD spectrum of of raw and acid treated kaolinite clay the range of $200-450{ }^{\circ} \mathrm{C}$ for their removal. The third weight loss region $\left(450-800{ }^{\circ} \mathrm{C}\right)$ was related to the structural hydroxyl groups. Comparing the weight loss of the parent and the acid treated clay it was observed that both samples contain the same amount of physisorbed water $(4.6 \%)$. The percentage loss for the parent clay in the range of $200-450{ }^{\circ} \mathrm{C}$ $(7.75 \%)$ was higher than that of the acid treated clay $(3.17 \%)$. This may be due to the fact that acid treatment increased the amount of amorphous silica and also surface area which made the water adsorption higher. On the contrary in the high temperature weight loss regions, the percentage loss is lower for acid treated clay as compared to the parent clay. It has been reported that the removal of the structural hydroxyl groups in $\left[\mathrm{AlO}_{6}\right]$ octahedral layer occurred along with the dissolving of $\mathrm{Al}^{3+}$ due to acid treatment. This result is in agreement with that of Panda et al. [28].

\subsubsection{Catalytic activity}

Oligomerization of isobutene over acid treated clay was carried out in gas phase and the effects of various parameters such as reaction temperature, reaction time and residence time (gas flow rate) on isobutene conversion and product selectivities were investigated. Analysis by GC-MS of the reaction products showed that the oligomerization of isobutene led to di-isobutene isomers (dimer-1 and dimer2) and tri-isobutene isomers (trimer-1 and trimer-2) as major products (Scheme 1). Tetraisobutene isomers (tetramer-1 and tetramer-2) were obtained as minor products.

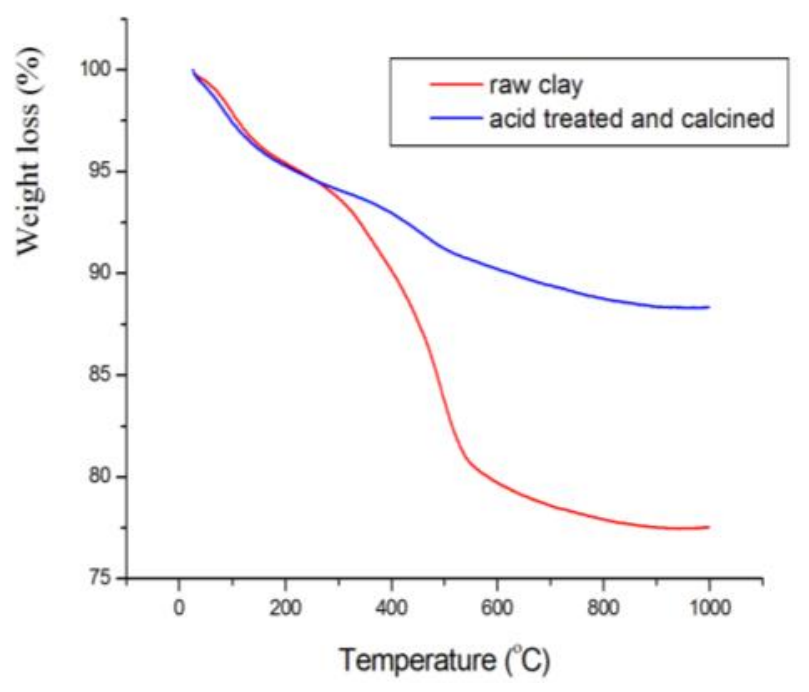

Figure 3. TG curves of raw and acid treated kaolinite clay 


\subsubsection{Effect of reaction temperature}

A series of experiments were conducted to investigate the effect of temperature on the IB oligomerization. Figure 4 illustrates the isobutene conversion and oligomers selectivity over the range of $40-70{ }^{\circ} \mathrm{C}$. The results show that the reaction temperature had a significant effect on the oligomerization reaction. As expected, increasing reaction temperature increased the conversion of isobutene. The conversion increased from 14 to $26 \%$ when the temperature increased from 40 to $60{ }^{\circ} \mathrm{C}$. However, when the reaction temperature reached $70{ }^{\circ} \mathrm{C}$, isobutene conversion decreased slightly.

The decrease of the conversion at high temperatures can be attributed to the deposition of olefins with high molecular weight during the reaction, which blocked active sites on the catalyst and decreased the catalytic activity [29,8, 30] or it might be due to the fact that cracking reactions occurred at higher temperatures and more dimers were generated accordingly to [31]. The total selectivity of dimer products (dimer-1 and dimer-2) decreased with reaction temperature increase. The decrease of dimers occurred in favor of trimers (trimer-1 and trimer-2) because trimers are formed from dimers by consecutive reactions. These results are in agreement with those reported in the literature [31,32]. Contrary to the selectivity of trimers, that of tetramers decreased with in-
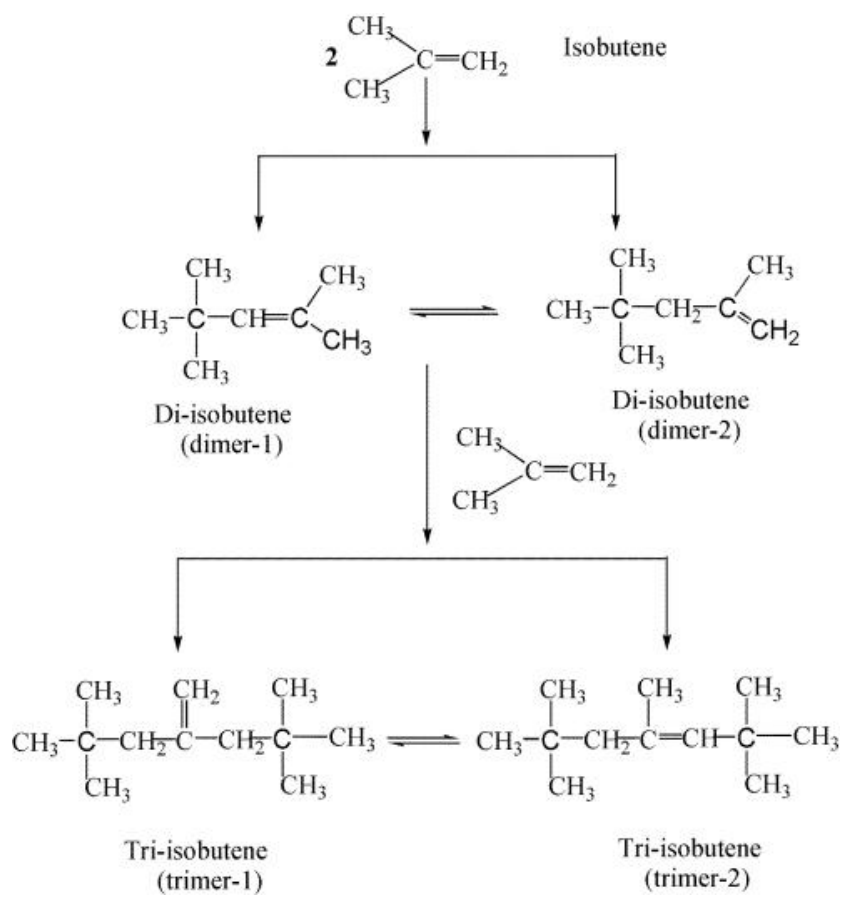

Scheme 1. Major products formed through oligomerization of isobutene over acid treated clay catalyst creasing temperature due to cracking reactions which occurred at higher temperatures.

Based on the above results, it can be suggested that relatively high reaction temperatures favored the conversion of isobutene and enhanced the formation of trimers. Based on the above results, $60{ }^{\circ} \mathrm{C}$ seems to be the optimum the reaction temperature. Therefore this temperature was selected for further investigations. The effect of reaction time and contact time on IB oligomerization was investigated.

\subsubsection{Effect of reaction time}

The conversion evolution as a function of time on stream at $60{ }^{\circ} \mathrm{C}$ is illustrated Figure 5. It can be seen from the figure that the conversion increased when the time increased from 1 to 3 hours then it decreased slightly. As for the selectivity, it can be seen that for both dimers and trimers no significant change was observed whereas a slight decrease in the selectivity of tetramers was obtained. This deactivation of the catalyst can be attributed to the formation of olefins with high molecular weight during the reaction, which blocked active sites on the catalyst and decreased the catalytic activity [29].

\subsubsection{Effect of contact time on the isobutene oligomerization}

The effect contact time (W/F) on the oligomerization of isobutene over the range of 14.4-58.3 s. is illustrated in Figure 6. As shown in the figure, when the contact time increased from 14.4 to $58.3 \mathrm{~s}$, the conversion increased

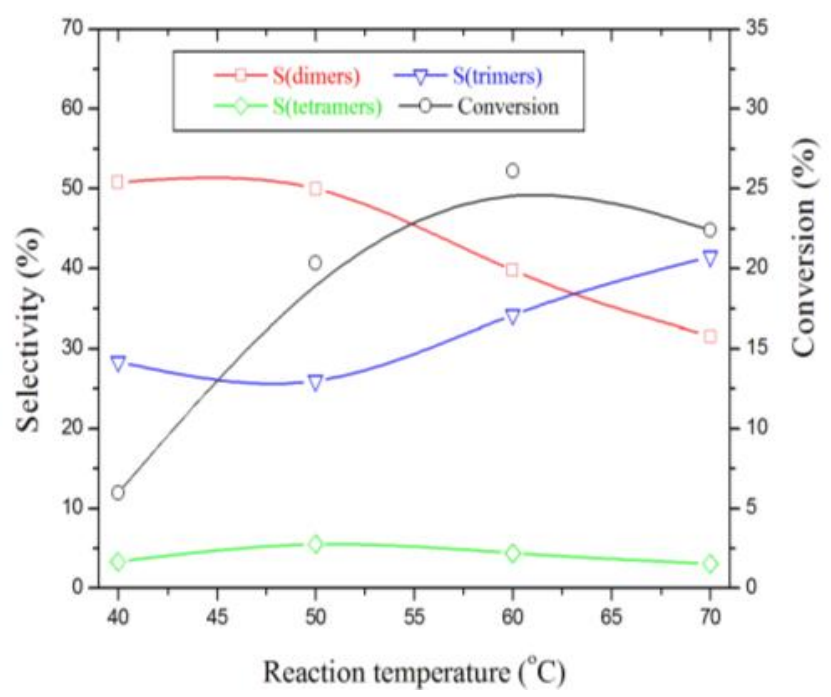

Figure 4. Effect of reaction temperature on isobutene conversion and product selectivities (residence time $0.012 \mathrm{~h}$ ) 
from 4.3 to $38.0 \%$ and the trimers increased from 26.7 to $37.1 \%$. In contrast the selectivity of dimers decreased from 53.0 to $39.0 \%$. This result was expected because dimers are converted into trimers by consecutive reactions. As for tetramers, a slight increase in their selectivity was observed for an increase in contact time from 14.4 to $28.8 \mathrm{~s}$ then a slight decrease with increased of contact time.

The decrease of the tetramers selectivity at longer contact times can be explained by the fact that when the contact time is too long, further oligomerization occurred which was evinced by GC-MS. Thus, at short contact times (14.4 to $28.8 \mathrm{~s}$ ) isobutene has not enough time to react which explains why the conversion is low. At high contact times (28.8 to $58.3 \mathrm{~s}$ ) the conversion is enhanced while the selectivity of dimers is decreased in favor of higher oligomers.

The effect of the contact time on the selectivity of all isomers, i.e. dimer-1, dimer-2, trimer1 , trimer-2, tetramer-1 and tetramer-2, has been also investigated. As shown in Figure 7, it has been found that the selectivity of dimer-1 was greater than that of dimer- 2 whereas, the selectivity of trimer-1 and tetramer-1 were lower than their corresponding trimer-2 and tetramer-2. This is can be explained by the fact that in dimer-1, the double bond is masked by a steric hindrance of alkyl groups. Therefore, it is less accessible to react with isobutene molecules. For dimer-2, the double bond is more exposed to be attacked by a molecule of isobutene which explains its conversion in trimer-2 and therefore the decrease of its selectivity.

Figure 8 shows the evolution of the isobutene oligomerization as a function of the conversion obtained at various contact times. As

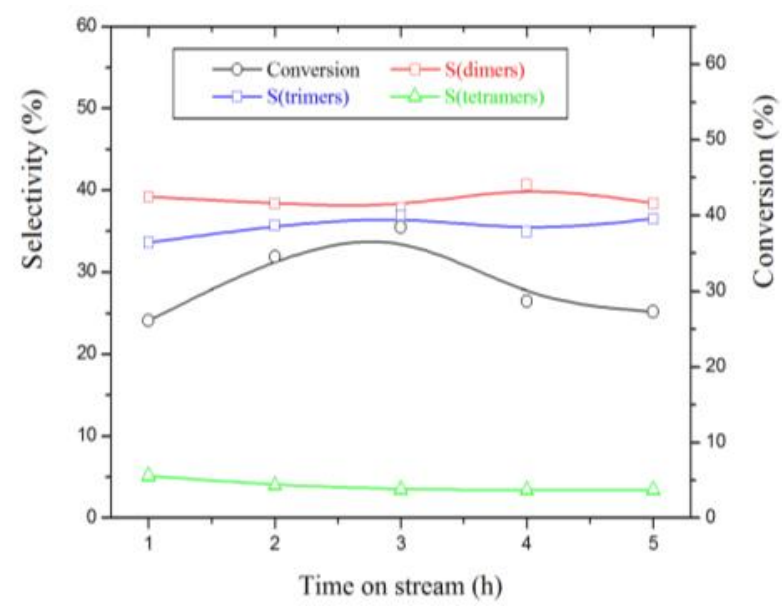

Figure 5. Conversion and selectivity of formed oligomers as a function of time in an experiment at $60{ }^{\circ} \mathrm{C}$ and residence time $0.012 \mathrm{~h}$ the conversion increases, the selectivity of dimers decreases while that of trimers increases. This result was expected because the oligomerization reaction is a consecutive reaction (from monomer to dimer, dimer to trimer, and trimer to tetramer) [13,33].

As for tetramer oligomers, it was noticed that at lower conversions, an increase of the selectivity was observed. In contrast at higher conversions a slight decrease in their formation occurred. The low selectivity of tetramers at high conversion might be due to the steric hindrance by the crowded alkyl groups [29]. Based on the above results, it can be suggested that the suitable conditions to enhance the selectivity of dimers are to conduct the reaction at relatively low reaction temperature and short contact time.

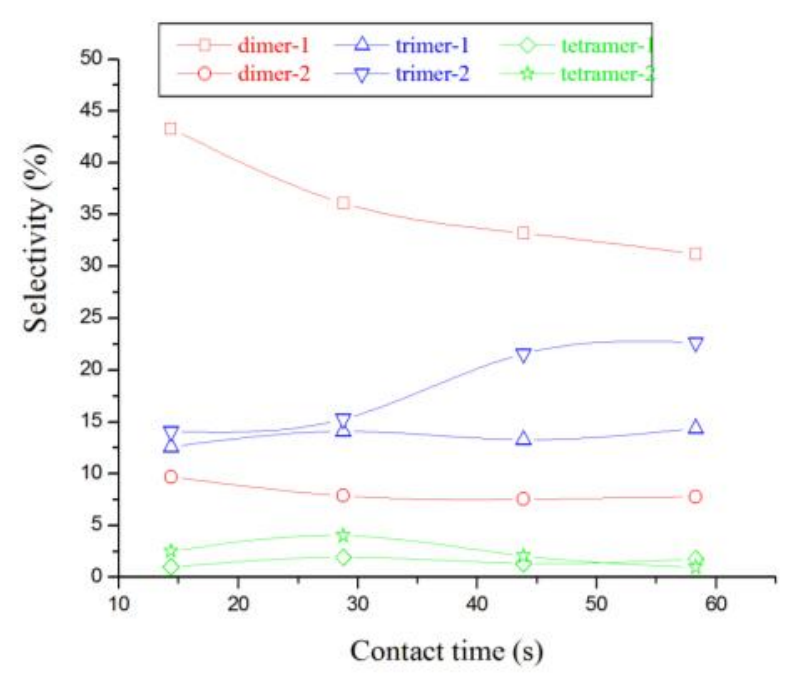

Figure 7. Variation of the oligomer selectivities with residence time for reactions conducted at $60{ }^{\circ} \mathrm{C}$

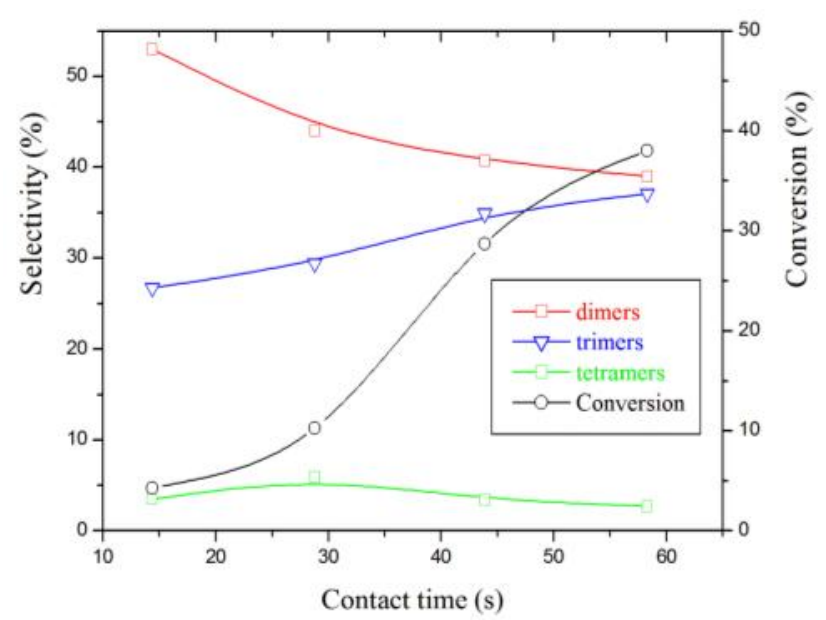

Figure 6. Variation of the conversion and selectivities with residence time for the reactions conducted at $60{ }^{\circ} \mathrm{C}$ 


\section{Conclusions}

The gas phase oligomerization of isobutene over acid treated Kaolin clay under mild reaction conditions was investigated. It has been found that the acid treatment $\left(\mathrm{H}_{2} \mathrm{SO}_{4} 5 \mathrm{M}\right)$ alter the chemical and structural properties of kaolin clay. The XRF results indicated a partial removal of $\mathrm{Al}_{2} \mathrm{O}_{3}, \mathrm{MgO}, \mathrm{CaO}$ and $\mathrm{Na}_{2} \mathrm{O}$ which resulted in an increase $\mathrm{SiO}_{2}$ content. XRD studies indicated that the crystallinity of the clay material was found to be altered by acid treatment. Crystalline kaolin clay became amorphous after acid treatment.

The catalytic performance of the acid treated kaolin clay for the isobutene oligomerization was investigated. It has been found that higher reaction temperatures increased both the conversion and trimers selectivity. The decrease of tetramers selectivity in favor of trimers at higher temperatures might be due to cracking reactions. By increasing the contact time the conversion was enhanced while the selectivity toward dimers was decreased in favor of higher oligomers. Therefore, the optimal conditions for dimers formation are relatively low reaction temperature and short contact time.

\section{Acknowledgement}

The Authors extend their appreciation to the Deanship of Scientific Research at King Saud University for funding the work through the research group project No RG-116.

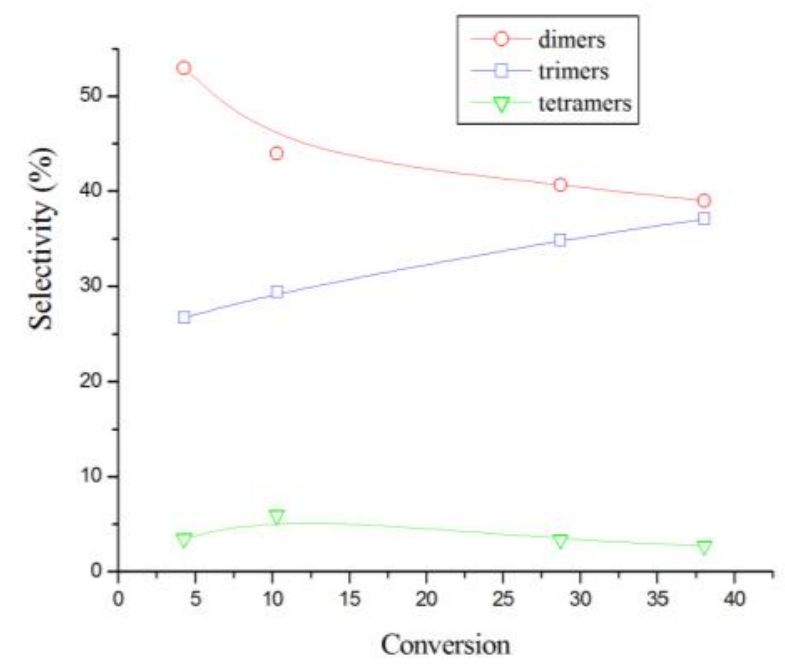

Figure 8. Dependence of the oligomer selectivities on the conversion for the reaction conducted at $60{ }^{\circ} \mathrm{C}$

\section{References}

[1] Burnes, E., Wichelns, D., Hagen, J.W. (2005). Economic and Policy Implications of Public Support for Ethanol Production in California's San Joaquin Valley. Energy Policy, 33: 1155-1167.

[2] Rossini, S. (2003). The Impact of Catalytic Materials on Fuel Reformulation. Catal. Today, 77: 467-484.

[3] Golombok, M., De Bruijn, J. (2001). Catalysts for Producing High Octane-Blending Value Olefins for Gasoline. Appl. Catal. A, 208: 4753.

[4] Chen, G., Li, J., Yang, X., Wu, Y. (2006). Surface-Appropriate Lipophobicity-Application in Isobutene Oligomerization over TeflonModified Silica-Supported 12-Silicotungstic Acid. Appl. Catal. A, 310: 16-23.

[5] Mantilla, A., Ferrat, G., Tzompantzi, F., López-Ortega, A., Romero, E., Ortiz-Islas E, Gómez R., Torres, M. (2004). Room Temperature Olefins Oligomerization over Sulfated Titania. Chem. Commun., 13: 14981499.

[6] Tzompantzi, F., Manríquez, M.E., Padilla, J.M., Del Angel, G., Gómez, R., Mantilla, A. (2008). One Pot Preparation of $\mathrm{NiO} / \mathrm{ZrO}_{2}$ Sulfated Catalysts and Its Evaluation for the Isobutene Oligomerization. Catal. Today, 133: 154-159.

[7] Lewis, J.M., Kydd, R.A. (1991). Adsorption Mechanism of Phosphoric Acid on $\gamma$-Alumina. J. Catal., 132: 465-471.

[8] Mantilla, A., Tzompantzi, F., Ferrat, G., Lopez-Ortega, A., Alfaro, S., Gómez, R., Torres, M. (2005). Oligomerization of Isobutene on Sulfated Titania: Effect of Reaction Conditions on Selectivity. Catal. Today, 107: 707-712.

[9] Lee, J.S., Yoon, J.W., Halligudi, S.B., Chang, J.S., Jhung, S.H. (2009). Trimerization of Isobutene over $\mathrm{WOx} / \mathrm{ZrO}_{2}$ Catalysts. Appl. Catal. A, 366: 299-303.

[10] Chellappa, A.S., Miller, R.C., Thompson, W.J. (2001). Supercritical Alkylation and Butene Imerization over Sulphatedzirconia and IronManganese Promoted Sulphated Zirconia Catalysts. Appl. Catal. A, 209: 359-374.

[11] Zhang, J., Kanno, M., Zhang, J., Ohnishi, R., Toriyabe, K., Matsuhashi, H., Kamiya, Y. (2010). Preferential Oligomerization of Isobutene in a Mixture of Isobutene and 1-Butene over Sodium-Modified 12-Tungstosilicic Acid Supported on Silica. J. Mol. Catal. A, 326: 107-112.

[12] Yoon, J.W., Chang, J.S., Lee, H.D., Kim, T.J., Jhung, S.H. (2007). Trimerization of Isobu- 
tene over a Zeolite Beta Catalyst. J. Catal., 245: 253-256.

[13] Hauge, K., Bergene, E., Chen D, Fredriksen G.R, Holmen, A. (2005). Oligomerization of Isobutene over Solid Acid Catalysts. Catal. Today, 100: 463-466

[14] Yoon, J.W., Jhung, S.H., Choo, D.H., Lee, S.J., Lee, K.Y., Chang, J.S. (2008). Oligomerization of Isobutene over Dealuminated Y Zeolite Catalysts. Appl. Catal. A, 337: 73-77.

[15] Makó, É., Senkár, Z., Kristóf, J., Vágvölgyi, V. (2006). Surface Modification of MechanoChemically Activated Kaolinites by Selective Leaching. J. Colloid Interf. Sci., 294: 362370.

[16] Volzone, C, Ortiga, J. (2011). SO 2 Gas Adsorption by Modified Kaolin Clays: Influence of Previous Heating and Time Acid Treatments. J. Environ. Manage., 92: 2590-2595.

[17] Kasprzhitskii, A., Lazorenko, G., Yavna, V., Daniel, Ph. (2016). DFT Theoretical and FTIR Spectroscopic Investigations of the Plasticity of Clay Minerals Dispersions. J. Mol. Struct., 1109: 97-105.

[18] Morsy, F.A., El-Sherbiny, S., Hassan, M.S., Mohammed, H.F. (2014). Modification and Evaluation of Egyptian Kaolinite as Pigment for Paper Coating. Powder Technol., 264: 430438.

[19] Bakhti, A., Derriche, Z., Iddou, A., Larid, M. (2001). A Study of the Factors Controlling the Adsorption of $\mathrm{Cr}$ (III) on Modified Montmorillonites, Eur. J. Soil Sci, 52: 683-692

[20] Frost, R.L, Vassallo, A.M. (1996). The Dehyddroxylation of the Kaolinite Clay Minerals using Infrared Emission Spectroscopy. Clays Clay Miner., 44: 635-651.

[21] Belver, C., Munoz, M.A.B., Vicente, M.A. (2002). Chemical Activation of a Kaolinite under Acid and Alkaline Conditions. Chem. Mater., 14: 2033-2043.

[22] Fan, Y., Wang, Q., Yang, X., Yao, J., Wang, G. (2009). Synthesis of Didodecyl Carbonate via Transesterification Catalyzed by $\mathrm{KF} / \mathrm{MgO}$. Chin. J. Chem. Eng., 17 (5): 883-886.

[23] Vaculíková, L., Plevová, E. (2005). Identification of Clay Minerals and Micas in Sedimentary Rocks. Acta Geodyn. Geomater., 2: 167175.
[24] Mohsen, Q., El-Maghraby, A. (2010). Characterization and Assessment of Saudi Clay Raw Material at Different Area. Arabian J. Chem., 3: 271-277.

[25] Gasparini, E., Tarantino, S.C., Ghigna, P., Pia Riccardi, M., Cedillo-González, EI., Siligardi, C., Zema, M. (2013). Thermal Dehydroxylation of Kaolinite under Isothermal Conditions. Appl. Clay Sci., 80: 417-425.

[26] Volzone, C., Ortiga, J. (2006). Removal of Gases by Thermal-Acid Leached Kaolinitic Clays: Influence of Mineralogical Composition. Appl. Clay Sci., 32: 87-93.

[27] Brown, G., Brindley, G.W. (1980) X-Ray Diffraction Procedures for Clay Mineral Identification. Pp. 305-359 in: Crystal Structures of Clay Minerals and their X-ray Identification (G.W. Brindley \& G. Brown, editors). Mineralogical Society, London.

[28] Panda, A.K., Mishra, B.G. (2010). Effect of Sulphuric Acid Treatment on the PhysicoChemical Characteristics of Kaolin Clay. Colloid Surface A: Physicochem Eng. Aspects, 363: 98-104.

[29] Sharma, M.M. (1995). Some Novel Aspects of Cationic Ion-Exchange Resins as Catalysts. React. Funct. Polym., 26: 3-23.

[30] Nkosi, B., Ng, F.T.T., Rempel, G.L. (1997). The Oligomerization of 1-Butene using Nay Zeolite Ion-Exchanged with Different Nickel Precursor Salts. Appl. Catal. A, 161: 153-166.

[31] Yang, S., Liu, Z., Meng, X., Xu, C. (2009). Oligomerization of Isobutene Catalyzed by Iron(III) Chloride Ionic Liquids. Energy Fuel, 23: 70-73.

[32] Liu, S., Shang, J., Zhang, S., Yang, B., Deng, Y. (2013). Highly Efficient Trimerization of Isobutene over Silica Supported Chloroaluminate Ionic Liquid using C4 Feed. Catal. Today, 200: 41-48.

[33] Yoon, J.W., Chang, J.S., Lee, H.D., Kim, T.J., Jhung, S.H. (2006). Trimerization of Isobutene over Cation Exchange Resins: Effect of Physical Properties of the Resins and Reaction Conditions. J. Mol. Catal. A, 260: 181186. 